\title{
THE BERNOULLI SOCIETY
}

The International Statistical Institute's section 'International Association for Statistics in Physical Sciences' has been reorganized and transformed into the Bernoulli Society for Mathematical Statistics and Probability.

The object of the Bernoulli Society is the advancement, through international contacts, of the sciences of probability (including the theory of stochastic processes) and mathematical statistics, and of their applications to all those aspects of human endeavour which are directed towards the increase of national knowledge and the welfare of mankind.

The Bernoulli Society is an open association and anyone interested in the objects of the Society may register as a member. The Statutes provide for the establishment of regional committees and of subject area committees. Three such standing committees have been established so far to continue and further develop the activities which were in the past undertaken by separate groups.

a. European Regional Committee

The Committee for the European Meetings of Statisticians has decided to be incorporated as a standing committee in the Bernoulli Society. The next meeting will be held in Grenoble (France), from 6-10 September 1976, while further European meetings are being planned. The Committee will initiate other activities of interest for European statisticians.

The chairman of the Committee is Professor J. Durbin (UK).

b. Committee for Conferences on Stochastic Processes

This Committee has in the past successfully organized several conferences and will continue this activity in the framework of the Bernoulli Society. The next conference is scheduled to take place in Israel, 7-11 June 1976.

The chairman of the Committee is Professor N. U. Prabhu (USA).

c. Committee for Statistics in the Physical Sciences

This Committee will be concerned with the activities inherited from the former international Association for Statistics in Physical Sciences.

The chairman of the Committee is Dr. F. Leone (USA).

The Bernoulli Society will hold its ordinary meetings during the biennial Sessions of the International Statistical Institute for which it will organize the programmes of meetings on mathematical statistics and probability. In addition, satellite symposia will be arranged while various committees have been set up to provide additional services to the members e.g. the possibility of reduced subscription rates of scientific journals.

The officers of the Bernoulli Society are:

President: D. Blackwell (USA)

President-Elect: K. Krickeberg (F. R. Germany), Scientific Secretary: J. Teugels (Belgium)

Treasurer: J. Durbin (UK), Executive Secretary: E. Lunenberg (ISI).

The first Council of the Bernoulli Society is composed as follows: D. R. Brillinger (Canada), G. K. Eagleson (Australia), J. Gani (Australia), A. H. Hald (Denmark), J. M. Hammersley (UK), M. Iosifescu (Romania), M. Kac (USA), L. M. LeCam (France), J. J. P. Neveu (France), W. R. van Zwet (Netherlands), D. Vere-Jones (New Zealand), M. Zelen (USA).

The annual membership dues have been fixed at 25 Swiss fancs.

Those wishing to join the Bernoulli Society should write to the Executive Secretariat in the Permanent Office of the International Statistical Institute, 428 Prinses Beatrixlaan, Voorburg, Netherlands. 


\title{
NOW AVAILABLE:
}

\section{PERSPECTIVES IN PROBABILITY AND STATISTICS}

\author{
Papers in honour of M. S. Bartlett on the occasion of his sixty-fifth birthday
}

Editor: J. GANI

\section{Contributors}

P. Armitage

N. T. J. Bailey

G. A. Barnard

A. Blanc-Lapierre

V. R. Cane

W. G. Cochran

J. W. Cohen

D. R. Cox

H. Cramér

H. E. Daniels

J. Gani

U. Grenander

J. M. Hammersley

E. J. Hannan

D. G. Kendall

J. F. C. Kingman

A. M. Kshirsagar

T. Lewis

P. D. M. Macdonald

P. Meier

P. A. P. Moran

C. R. Rao

C. A. B. Smith

H. Solomon

L. Takács

P. Tautu

D. Vere-Jones

P. Whittle

E. J. Williams

H. Wold

Publishers:

Sole distributors:
This book is an affectionate tribute to Professor M. S. Bartlett from 30 colleagues in Britain, Europe, North America, India, Australia and New Zealand. It honours both the man and his fundamental contributions to probability and statistics. Bartlett's breadth and versatility in these fields over the past 40 years are reflected in the variety of subjects touched upon by the authors; their papers include a historical introduction, studies in probability theory, statistical theory, mathematical methods in probability and statistics, stochastic processes and inference on such processes, probability models in the physical and social sciences, and finally some surveys in biomathematics and epidemiology.

In their papers, the contributors have acknowledged their scientific and personal indebtedness to Bartlett as a teacher and colleague.

APPLIED PROBABILITY TRUST

Department of Probability and Statistics, The University, Sheffield S3 7RH, England.

ACADEMIC PRESS INC. (LONDON) LTD. 24-28 Oval Road, London NW1, England.

Price: U.K. $£ 8.50 \quad$ U.S.A. $\$ 21.00$

Orders should be placed with the sole distributors either directly or through a bookseller. 


\section{Advances in Applied Probability}

The Editorial Board would like to encourage the submission to the Advances of Review Papers summarising and coordinating recent results in any of the fields of Applied Probability.

In addition to these Review Papers, Advances is also designed to be a medium of publication for (1) longer research papers in Applied Probability, which may include expository material, (2) expository papers on branches of mathematics of interest to probabilists, (3) papers outlining areas in the biological, physical, social and technological sciences in which probability models can be usefully developed, and finally, (4) papers in Applied Probability presented at conferences which do not publish their proceedings.

In short, the main function of Advances is to define areas of recent progress and potential development in Applied Probability. As with the Journal of Applied Probability, Advances undertakes to publish papers accepted by the Editors within 15 months of their submission.

The Editorial Board consists of E. Sparre Andersen, V. D. Barnett, D. Blackwell, V. R. Cane, J. W. Cohen, B. Gnedenko, J. Hájek, E. J. Hannan, C. C. Heyde, J. Keilson, D. G. Kendall, J. F. C. Kingman, K. Krickeberg, R. M. Loynes, P. A. P. Moran, J. Neveu, K. R. Parthasarathy, N. U. Prabhu, R. Pyke, C. A. B. Smith and L. Takács. The Editor-in-Chief is J. Gani, and the Editorial Office of the Advances is in the Department of Probability and Statistics, The University, Sheffield S3 7RH, England.

Volume 8 No. 2 of Advances contains the following papers:

FIFTH CONFERENCE ON STOCHASTIC PROCESSES AND THEIR APPLICATIONS V. I. KRYUKOV MICHAEL SZE

\section{ANDREW D. BARBOUR MARTHA J. SIEGEL}

\author{
W. DUNSMUIR AND \\ E. J. HANNAN \\ P. WHITTLE AND \\ J. F. RUDGE \\ P. BRÉMAUD \\ D. J. DALEY \\ F. P. KELLY
}

University of Maryland, 9-13 June 1975

\begin{abstract}
Wald's identity and random walk models for neuron firing Markov processes associated with critical Galton-Watson processes with application to extinction probabilities Quasi-stationary distributions in Markov population processes The asymptotic behavior of a divergent linear birth and death process
\end{abstract}

Vector linear time series models

Simultaneous communication and control

Bang-bang controls of point processes

Queueing output processes

Networks of queues

Subscription rates (per volume) for Advances in 1976 are the same as for the Journal, namely:

For libraries and institutions:

U.S.\$43.20 £18.00

For individuals belonging to a recognised scientific society:

U.S. $\$ 14.40 £ 6.00$

$10 \%$ discount is allowed to subscribers who order current issues of both the Journal and Advances at the same time direct from the Editorial Office. The prices are as follows:
For libraries and institutions:
U.S.\$77.75 $\$ 32.40$
For individuals:
U.S.\$25.90 $£ 10.80$

Prices of back issues on application to the Executive Editor.

Cheques made out on U.S., U.K. and Australian banks will be acceptable: they should be made payable to Applied Probability, and sent to:

Executive Editor, Advances in Applied Probability,

Department of Probability and Statistics,

The University, Sheffield S3 7RH, England. 


\title{
Publications of the Applied Probability Trust
}

\author{
Methuen's Supplementary Review Series in Applied Probability
}

General Editor: M. S. Bartlett, M.A., D.Sc., F.R.S. Editor: J. Gani, D.I.C., Ph.D., D.Sc., F.A.A.

The following titles in this series are still available; the papers appeared in the earlier volumes of the Journal of Applied Probability.
Volume 2 M. Kimura:
Diffusion models in population genetics
Volume 3 E. J. Hannan:
Group representations and applied probability
Volume 5 S. Kotz:
Recent results in information theory
Volume 6 J. F. C. Kingman: On the algebra of queues

Price per volume: $£ 0.50$ (US $\$ 1.25 ; \$ A .1 .00$ ).

Proceedings of the WHO Symposium on Quantitative Epidemiology (Moscow, November 1970): reprinted from Advances in Applied Probability, Volume 3.

Price per copy: $£ 0.50$ (US $\$ 1.25 ; \$ A .1 .00$ ).

Proceedings of the Conference on Directions for Mathematical Statistics

held at the University of Alberta, Edmonton, Canada, 12-16 August 1974.

This title was issued as a special supplement to Adv. Appl. Prob. Volume 7 No. 3.

A limited number of copies are still available at the price of $£ 1.50$ (US $\$ 3.50 ; \$ A .2 .40$ ).

Orders for the above should be sent to

Applied Probability, Dept. of Probability and Statistics, The University, Sheffield S3 7RH, England.

All orders should be accompanied by a remittance, payable to 'Applied Probability'.

\section{Mathematical Spectrum: A magazine of contemporary mathematics}

This magazine addresses itself primarily to young mathematicians in schools, colleges of education and universities. Its object is to discuss the entire range of modern mathematical disciplines in an informative but informal manner and to relate discoveries in mathematics to progress in the natural sciences, technology, social studies and business management.

The Editors believe that the process of learning is a dialogue and consequently they wish to promote active participation by readers. Correspondence on any subject relating to mathematics and mathematical education is welcomed. There is also a problem section, and readers are encouraged to submit their solutions, the best of which are published.

For further information and a detailed price list application should be made to

Editor - Mathematical Spectrum (Ref. AP)

Hicks Building, The University,

Sheffield S3 7RH, England. 


\section{Subscription rates}

Subscriptions (post free) for the 1976 volume of the Journal are:

U.S. $\$ 43.20$, £stg. 18.00, for libraries and institutions;

U S. $\$ 14.40$, £stg. 6.00 , for individuals belonging to a recognised scientific society.

Members of the London Mathematical Society should apply direct to the Secretary of the Society for copies of the Journal.

All enquiries about the Journal, as well as other subscriptions and orders for back numbers should be sent to the Executive Editor, Miss M. Hitchcock, Department of Probability and Statistics, The University, Sheffield S3 7RH, England. The price of back numbers varies from volume to volume, and enquiries should be sent to the Executive Editor. Cheques, money orders, etc. should be made out to Applied Probability; cheques on U.S., U.K. and Australian banks will be acceptable.

\section{Notes for Contributors}

Submission of papers

It is a condition of publication in the Journal of Applied Probability that papers shall not previously have appeared elsewhere, and will not be reprinted without the written permission of the Trust. The copyright of all published papers shall be vested in the Trust. It is the general policy of the Journal not to accept for publication papers which cannot appear in print within 15 months of their date of submission. Authors will receive 50 reprints of their papers free, and joint authors a proportional share of this number. Additional reprints will be provided at cost.

Manuscripts should be written in English or French; manuscripts in other languages may be accepted by the Editors, but will appear (subject to the author's agreement) in English or French translation in the Journal. Authors are requested to comply with the following instructions in submitting their papers:

Authors in Britain, Europe, North and South America should send three copies of their submissions to the Applied Probability Office in Sheffield.

Authors in Australasia and the Far East should send three copies of their submissions to the Editor-in-Chief, Dr. J. Gani, in Canberra.

The Editor-in-Chief and the Applied Probability Office are in direct contact by Telex, and full details of the papers submitted either in Sheffield or Canberra are available in both centres.

Alternatively, authors may submit papers to any one of the Editors listed on the inside front cover. In this case, two copies of the submission should be sent to the Editor concerned, and one copy, with a copy of the covering letter, should be sent to the Applied Probability Office in Sheffield.

\section{Journal conventions}

It will be of help to the Editors if the following conventions are adopted:

a) The manuscript should be typewritten, using double spacing, on one side of the paper only.

b) Each paper submitted should be accompanied by

(i) a short abstract of approximately 4-10 lines giving a non-mathematical description of the subject matter and results;

(ii) a list of keywords detailing the contents for the purpose of computerised information retrieval.

c) References should be indicated in the text by the name of the author(s) and the date, thus: Feller (1961), and the full references listed at the end of the article in alphabetical order. Journal references should include the title of the article cited, the title of the journal (abbreviated in the style of the International Journal of Abstracts: Statistical Theory and Method), the volume, and inclusive page numbers. Book references should give the full title, the publisher, and the place of publication. For example:

Feller, W. (1961) A simple proof of renewal theorems. Comm. Pure Appl. Math. 14, 285-293.

Robinson, E. A. (1959) An Introduction to Infinitely Many Variates. Griffin, London

d) Type faces should be carefully distinguished on the manuscript using the following standard methods of marking:

Italic capitals $(T, I, R)$ and lower case letters $(t, i, r)$ should be underlined once, e.g. $\underline{T}, \underline{I}, \underline{R}, \underline{t}, \underline{i}, \underline{r}$. Bold-face capitals $(T, I, R)$ and lower case letters $(t, i, r)$ should have a curly underline, e.g., $\underset{\sim}{\mathbf{T}}, \mathbf{I}, \underset{\sim}{\mathbf{R}}, \underline{\mathbf{t}}, \underset{\sim}{\mathbf{i}} \underset{\sim}{\mathbf{r}}$. Greek characters $(\alpha, \beta, \theta)$ and script letters $(\mathscr{J}, \mathscr{I}, \mathscr{R})$ should be carefully drawn and identified when first used by a marginal note of the form ' $\alpha$-lower case Greek alpha' or ' $\mathscr{R}$-script R'.

e) Indices and subscripts should be clearly distinguished, using the marking $4, \widehat{4}$ where necessary.

Authors will receive only first proofs for correction; charges will be made for excessive alteration to these.

Printed in Israel at the Jerusalem Academic Press, P.O.B. 2390, Jerusalem. 


\section{CONTENTS}

P. HOLGATE KENNY S. CRUMP AND JOHN H. GILLESPIE

J. GANI AND I. W. SAUNDERS

I. W. SAUNDERS

R. A. DONEY

WARREN W. ESTY

B. D. RIPLEY

C. PARK AND

F. J. SCHUURMANN

ROBERT J. ADLER

R. T. SMYTHE

N. R. MOHAN

MYNDA SCHREUER

PYKE TIN AND

R. M. PHATARFOD

J. RADCLIFFE

ROBERT C. WANG

SALLY I. MCCLEAN

AIDAN SUDBURY

PEDRO VIT

M. E. SOLARI AND

J. E. A. DUNNAGE

HOLGER ROOTZÉN DOUGLAS P. KENNEDY

A. M. HASOFER

MATTHEW GOLDSTEIN

Y. H. WANG

N. L. JOHNSON AND SAMUEL KOTZ I. GERTSBACH

L. $R \AA D E$

R. BERGMANN AND D. STOYAN HELMUT WEGMANN

STIG I. ROSENLUND

\section{Research Papers}

201 The total number of heterozygotes before fixation

208 The dispersion of a neutral allele considered as a branching process

219 On the parity of individuals in a branching process

231 A convergence theorem for parities in a birthand-death process

239 On single- and multi-type general age-dependent branching processes

247 Diffusion limits of critical branching processes conditioned on extinction in the near future

255 The second-order analysis of stationary point processes

267 Evaluations of barrier-crossing probabilities of Wiener paths

276 Excursions above a fixed level by $n$-dimensional random fields

290 Remarks on renewal theory for percolation processes

301 Limit distributions of the number of renewals and waiting times

313 Stochastic pursuit-evasion games with information lag. II. Observation with error

329 Some exact results for dams with Markovian inputs

\section{Short Communications}

338 The convergence of a position-dependent branching process used as an approximation to a model describing the spread of an epidemic

345 The extinction time of Markov branching processes

348 A continuous-time population model with Poisson recruitment

355 The size of the region occupied by one type in an invasion process

357 On the equivalence of certain Markov chains

361 A note on Spitzer's lemma and its application to the maximum of partial sums of dependent random variables

365 Gordin's theorem and the periodogram

371 The distribution of the maximum Brownian excursion

377 The mean number of maxima above high levels in Gaussian random fields

380 A bound for bivariate probability of large deviations

385 A functional equation and its application to the characterization of the Weibull and stable distributions

392 On a multivariate generalized occupancy model

400 Sufficient optimality conditions for control-limit policy in a semi-Markov process

407 Reliability systems in random environment

411 On exponential bounds for the waiting-time distribution function in $G I / G / 1$

418 The capacity of an intersection with non-stationary traffic

423 Recurrent emptiness in a finite queue with increasing arrival rate 